\title{
Study of the Mechanical Behavior of an Automobile Brake Disc
}

\author{
Kerrouz Siham¹, Bourdim Mokhtar ${ }^{2 *}$, Tamine Tawfik¹, Bouchtara Mostefa1 \\ ${ }^{1}$ Laboratory of Gaseous Fuel and Environment (LCGE), Department of Mechanical Engineering, University of Science and \\ Technology of Oran Mohamed-Boudiaf, 31000 Bir El Djir, El Mnaouar, Oran, P. O. B. 1505, Algeria \\ ${ }^{2}$ Laboratory of Industrial Engineering and Suitable Development, Department of Mechanical Engineering, Ahmed Zabana \\ University, 48000 Relizane, Bourmadia, Algeria \\ * Corresponding author, e-mail: mokhtar.bourdim@cu-relizane.dz
}

Received: 16 January 2020, Accepted: 01 January 2021, Published online: 07 June 2021

\begin{abstract}
An automobile brake disc brought into contact with the pads, mechanical stresses are imposed on the contact surface. These stresses can cause degradation by fatigue, rupture, wear, propagation of cracks. Modeling the numerical results makes it possible to recognize this damage in order to improve the braking system, extend its service life, reduce the cost of maintenance and make it more reliable. The aim of our study concerns modeling and numerical simulation using ANSYS 14.5 software based on the finite element method under the influence of certain essential parameters on the braking behavior of the torque as a function of geometric parameters, properties mechanical, boundary conditions, type of loading applied, type of materials chosen and type of analysis carried out in braking torques (ventilated drilled disc / pads and ventilated grooved disc / pads), upon contact with a disc in rotation with a plate which represents the friction body on the disc. The behavior of the torque during braking was analyzed in terms of stresses and deformations, and displacements, the comparison between the two types of discs was also discussed.
\end{abstract}

Keywords

automobile, disc, brake, pads, stresses, fatigue, parameters, rotation, deformations, displacements

\section{Introduction}

Tribology is a part of mechanics dealing with friction and its effects, such as wear, lubrication and contact. When two solids in contact are set in motion with respect to each other, they produce an opposing force in motion.

A tribological system is defined as a mechanical system, formed of two materials in contact, like the braking system that we use in this study.

There are several braking technologies, practiced in several vehicles of all types, light or heavy, they are used throughout the automotive industry, railways and aeronautics. Disc brakes are the most popular and most used, they are considered to be reliable and more efficient, they exist in different types; solid discs, ventilated discs and others such as drilled discs and grooved discs. The brake disc is a key organ in braking systems, guaranteeing safety, it remains very studied by engineers. and is part of friction brakes, a ubiquitous and widely used technology, as motion braking technology, in the automotive, aeronautical, railway and other fields. Associated with brake pads, the brake disc constitutes a tribological system (brake disc / brake pads); a tribological system, of course, subject to friction and confronted with wear.
In most mechanical systems, there are situations in which a deformable body comes into contact with other bodies. The problem of contact is essentially to know how the forces are applied to a structure and how the latter react in particular in the presence of friction. Understanding these problems is a key issue. Numerical simulation by the finite element method of these complex phenomena is most often used in the numerical resolution of these problems.

In a braking system when a rotating disc comes into contact with a pad, a pressure force is applied via loads, to the support pressing the pads on the disc, mechanical energy is transformed into energy thermal this energy generates a heating of the couple (disc / pads) and the rapid increase of the temperature at the level of the contact zone in the first seconds. A modeling of the behavior of the torque (disc / pads) in a braking system is adopted for the certification of these two bodies. This method aims to know the surfaces damaged during braking and therefore to quantify the effect of deterioration on the mechanical performance of these organs in contact, this will allow us to make an optimal and economical choice of discs and pads more resistant to damage. 


\section{Comparison of the braking behavior of the two couple (discs / pads)}

Our choice was focused on a numerical simulation carried out using a WORKBENCH ANSYS 14.5 calculation code in order to carry out an investigation on the mechanical behavior of the braking system during stopping braking, and to present a modeling for predicting damage after contact between the disc and the pad under braking conditions.

In this simulation we study two types of discs (ventilated grooved disc and ventilated pierced disc) with a single plate. We are interested in the mechanical contact of a flexible insert made of an organic matrix composite material with a rigid disc of gray cast iron. The contact pressure applied to the brake pad at a force of $1 \mathrm{MPa}$ puts it in rubbing contact with the disc, the angular speed of which $\omega=152.28 \mathrm{rpm}$ is kept constant throughout the simulation The coefficient of friction $\mu=0.2$ remains constant during braking. The behavior of the disc / pad braking couple during braking was analyzed in terms of stresses and deformations, and displacements. The influence of the variation of a few parameters on the torque response was also analyzed.

\section{Disc types}

Fig. 1 illustrates the choice of the two types of discs chosen; perforated ventilated disc formed by two solid parts superimposed with a space between the two to improve cooling, the drilling of the discs also allows cooling, and cleaning of the discs $[1,2]$. Grooved ventilated disc which offers superior mechanical resistance, the outward-facing grooves ensure the dispersion of any water present on the surface of the disc [3-5].

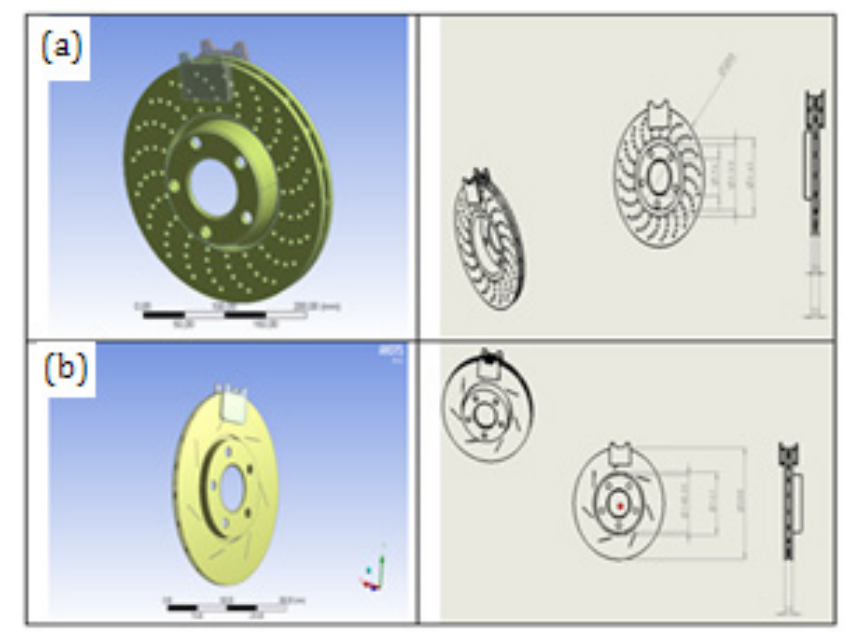

Fig. 1 Geometries of the two couple (discs / pads): (a) Couple ventilated drilled disc / pads; (b) Couple ventilated grooved disc / pads

\subsection{Materials of components of the couple (disc / plate)}

Brake pads are made up of two components; the mild steel support, to distribute the force exerted by the piston over the entire surface of the linings. The linings are organic matrix composite materials, which must have a high and stable coefficient of friction with low wear rate whatever the variations in temperature, pressure or speed with low wear rate $[4,5]$.

In the automotive industry, the disc is made of gray cast iron for multiple reasons, such as ease of manufacture; it also has good conductivity, fairly good mechanical strength, and low wears [6]. Table 1 show the mechanical characteristics of these materials.

\subsection{Mesh of the two couples}

The entire brake system has been discretized using finite elements. ANSYS WORKBENCH performs an automatic mesh (by default). Fig. 2 gives respectively a volume mesh of a disc and a brake pad in the same coding and the same material as shown in Table 1.

\section{3 conditions of the two couples}

In Fig. 3, we have defined the boundary conditions in order to highlight the finest meshes to have a better view of the parts that interest us.

Table 1 Mechanical characteristics of these materials used to make the couple (disc / pad).

\begin{tabular}{lcc}
\hline Material properties & disc & Brake pads [7] \\
\hline Density $\left(\mathrm{kg} / \mathrm{m}^{3}\right)$ & 7200 & 2500 \\
Young's modulus $(\mathrm{Pa})$ & $1.1 \mathrm{E}+11$ & $3 \mathrm{E}+09$ \\
Poisson coefficient & 0.3 & 0.25 \\
$\begin{array}{l}\text { Compressibility } \\
\text { Modulus (Pa) }\end{array}$ & $8.3333 \mathrm{E}+10$ & $2 \mathrm{E}+09$ \\
Shear modulus $(\mathrm{Pa})$ & $4.2969 \mathrm{E}+10$ & $1.2 \mathrm{E}+09$ \\
\hline
\end{tabular}

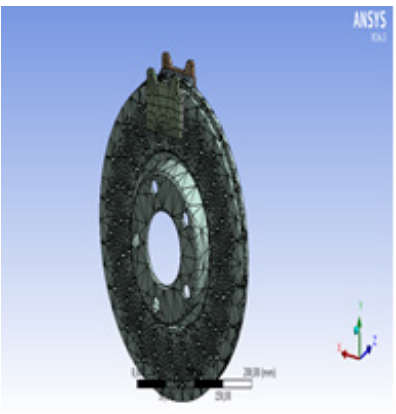

(a)

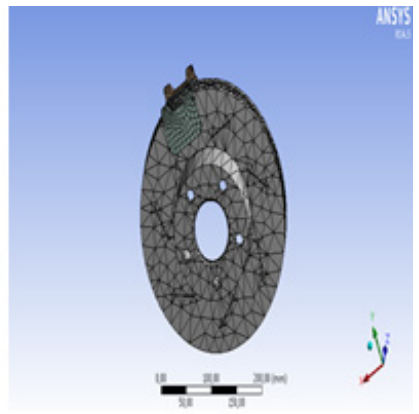

(b)
Fig. 2 Mesh of the couples; (a) Mesh of the couple (drilled disc / pads); (b) Mesh of the couple (grooved disc / pads) 


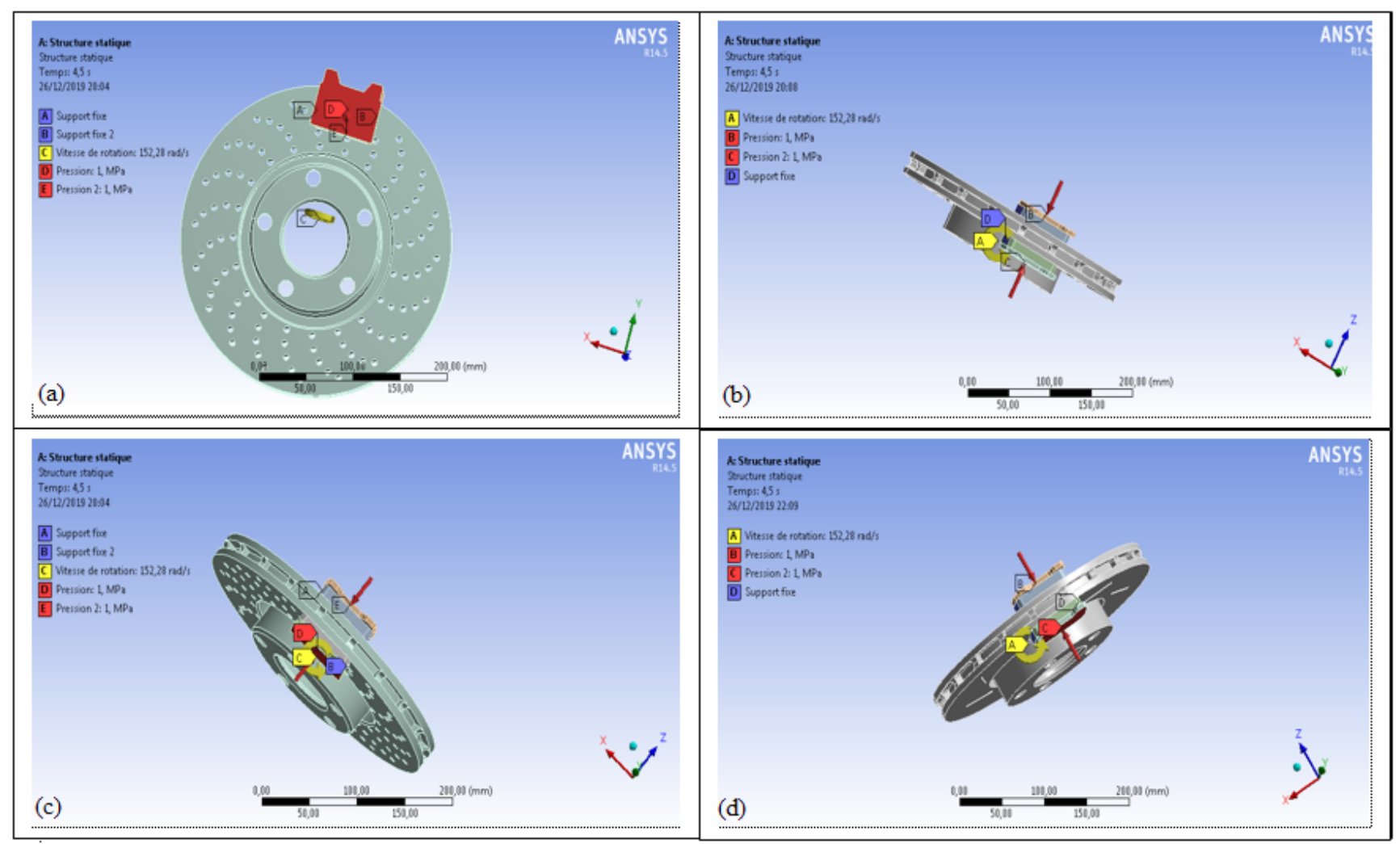

Fig. 3 Conditions to limits; (a) Front view of the boundary conditions and the load applied to the drilled brake disc-pads; (b) profile view of the boundary conditions and the load applied to the grooved brake disc / pads; (c) profile view of the boundary conditions and the load applied to the drilled brake disc / pads; (d) profile view of the boundary conditions and the load applied to the grooved brake disc / pads

\subsection{Vehicle data}

Table 2 presents the data of the characteristics of the vehicle studied.

\section{Results and discussions}

4.1 Comparison between the two braking torques (ventilated drilled disc / pads and ventilated grooved disc / pads)

\subsubsection{Répartition du champ des contraintes équivalentes de Von Mises}

Fig. 4 shows that the comparison between the two couples as a function of time.

A high concentration of stresses is localized in the contact zone for the two couples at the level of the groove oriented towards the outside, and at the level of the perforations. It propagates towards the zone of track-bol and towards the ventilation fins with low values. The perforated disc supports better than the grooved disc, thanks to the perforations, which allow the disc to cool faster than the grooved disc and guarantees a better heat dissipation capacity compared to the grooved disc. Therefore, the drilled disc ensures good thermal behavior.

\begin{tabular}{lc}
\multicolumn{2}{c}{ Table 2 Characteristics of the vehicle } \\
\hline Characteristics & Values \\
\hline Vehicle mass M $[\mathrm{kg}]$ & 1700 \\
Radius of the wheel R $[\mathrm{mm}]$ & 295.5 \\
Radius of the drilled disc $r[\mathrm{~mm}]$ & 144 \\
Radius of the grooved disc $r[\mathrm{~mm}]$ & 144 \\
Initial speed $v_{0}[\mathrm{~m} / \mathrm{s}]$ & 45 \\
Angular speed $\omega[\mathrm{rd} / \mathrm{s}]$ & 152.28 \\
Pad area A $\left[\mathrm{mm}^{2}\right]$ & 7471.2 \\
Force working on the disc $\mathrm{F}[\mathrm{N}]$ & 1494.22 \\
Pressure which comes to press the disc $\mathrm{P}[\mathrm{MPa}]$ & 1 \\
\hline
\end{tabular}

Fig. 5 shows that for the grooved disc, the values of the Von-Mises equivalent stress vary from $0 \mathrm{MPa}$ to 122.42 $\mathrm{MPa}$, on the other hand for the pierced disc the values are from $0 \mathrm{MPa}$ to $64.103 \mathrm{MPa}$. The maximum value of the equivalent stress appears in the grooved disc; the difference is quite large in the order of $58.317 \mathrm{MPa}$. 


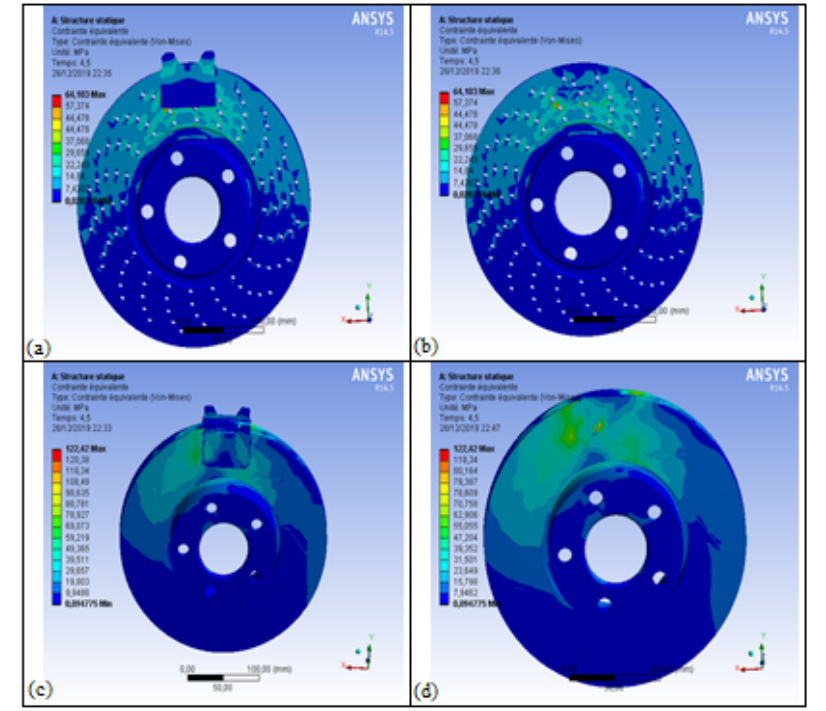

Fig. 4 Distribution of the Von-Mises equivalent stress in the two couples as a function of time $(t=4.5 \mathrm{~s})$.

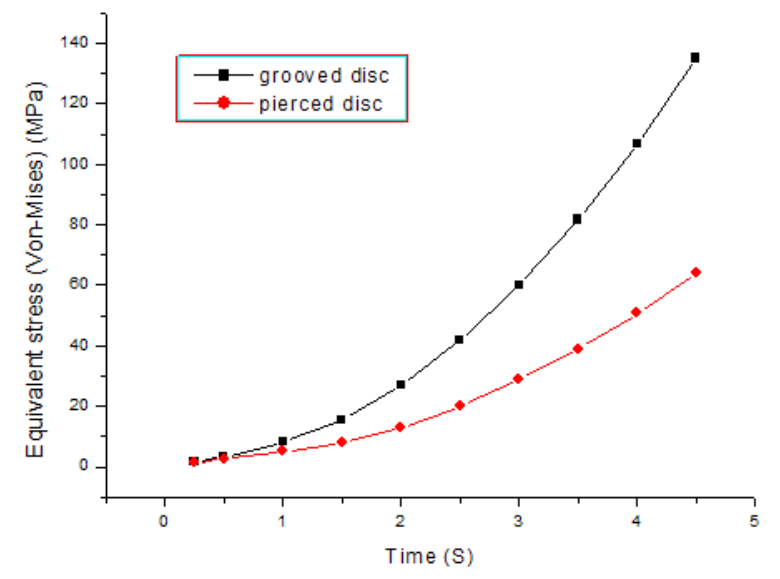

Fig. 5 The variation of the equivalent stress in the two couples a function of time

\subsection{Influence of material change for the two couples} (ventilated grooved disc / pads, and ventilated perforated disc / pads)

4.2.1 Influence of change of material for the two types of the disc on the variation of the field of Von-Mises equivalent stress

For the other materials composing the discs, which are respectively, FG15, stainless steel, the mechanical properties are given in the Table 3 .

From the results in Fig. 6, it can be seen that after braking, which is an application of the friction contact between the discs and the linings. The discs undergo severe damage (cracking resulting from thermal fatigue, streaks are formed on the friction surfaces due to dirt, foreign body
Table 3 Mechanical properties for the torque (FG25, FG15, stainless steel / composite)

\begin{tabular}{|c|c|c|c|}
\hline Characteristics & Material 1 & Material 2 [8] & Material 3 \\
\hline $\begin{array}{l}\text { Mechanical } \\
\text { Properties }\end{array}$ & FG25 & FG15 & Stainless steel \\
\hline Density $\left[\mathrm{Kg} / \mathrm{m}^{3}\right]$ & 7200 & 7250 & 7750 \\
\hline $\begin{array}{l}\text { Young's modulus } \\
\text { [Pa] }\end{array}$ & $1.1 \mathrm{E}+11$ & $1.38 \mathrm{E}+11$ & $1.93 \mathrm{E}+11$ \\
\hline $\begin{array}{l}\text { Poisson's } \\
\text { coefficient }\end{array}$ & 0.28 & 0.28 & 0.31 \\
\hline $\begin{array}{l}\text { Compressibility } \\
\text { modulus }[\mathrm{Pa}]\end{array}$ & $\begin{array}{l}8.3333 \mathrm{E} \\
+10\end{array}$ & $1.0455 \mathrm{E}+11$ & $1.693 \mathrm{E}+11$ \\
\hline Shear modulus $[\mathrm{Pa}]$ & $\begin{array}{l}4.2969 \mathrm{E} \\
+10\end{array}$ & $5.3906 \mathrm{E}+10$ & $7.3664 \mathrm{E}+10$ \\
\hline
\end{tabular}

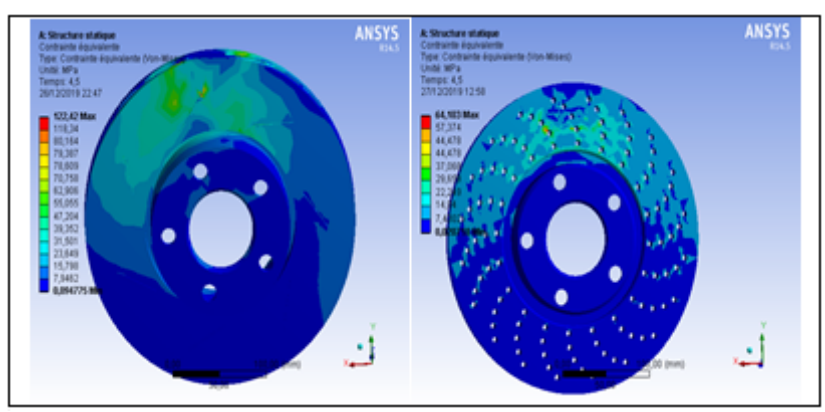

(a)

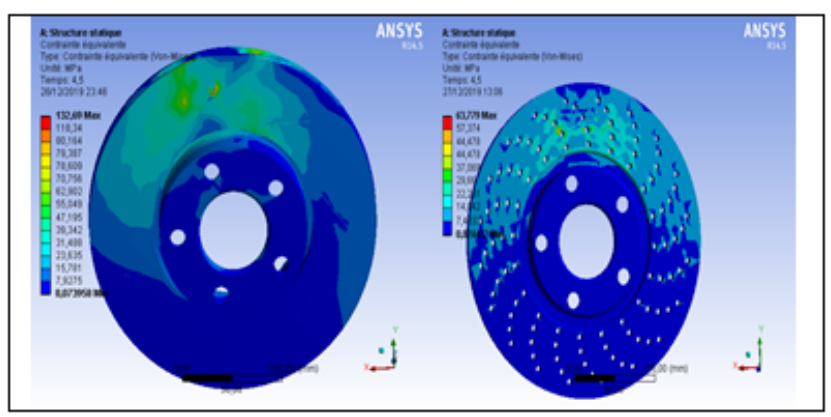

(b)

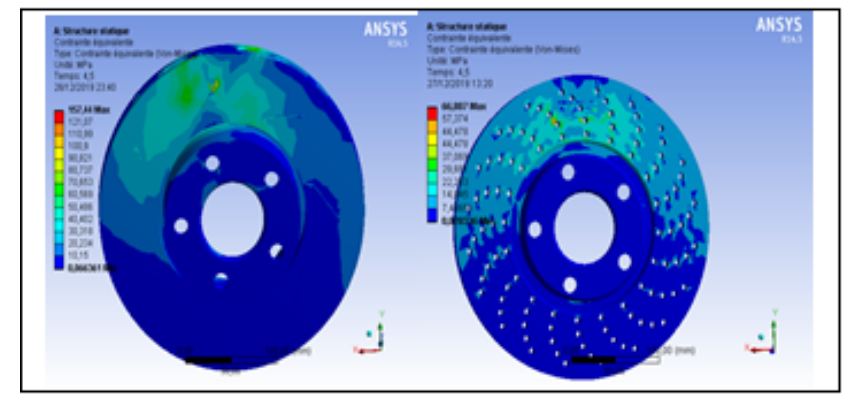

(c)

Fig. 6 Comparison between the three torques under the influence of change of the disc material over time; (a) disc (FG25) / pads composite; (b) FG 15 disc / pads (composite); (c) disc (stainless steel) / pads (composite) 
between the disc and the lining, corrosion, etc.). The change of materials plays an important role in the mechanical behavior of braking torques. To reduce this damage, we use materials that had better withstand thermal and mechanical effects, which is what prompted us to do a study on the latter by varying the material of the discs.

Fig. 7 shows that the greatest value of the equivalent stress appears in the couple (stainless steel / organic matrix composite) for the two types of disc, which are respectively, pierced disc, and grooved disc, the values vary from $66.887 \mathrm{MPa}$ to $157.44 \mathrm{MPa}$, while the lowest values are at the torque level (FG25 / organic matrix composite) and vary from $64.103 \mathrm{MPa}$ to $122.42 \mathrm{MPa}$, due to the low Young modulus, while in the torque (FG15 / organic matrix composite) varies from 63.779 $\mathrm{MPa}$ to $132.69 \mathrm{MPa}$.

Therefore, it is clear why gray cast iron is most commonly used in the automotive industry which has a high carbon content, it ensures good thermal behavior and good mechanical resistance, deprives the breaking strength and the elasticity module, with low wear, can better resist cracking despite the high temperature [5, 8-10].

\subsubsection{Influence of change in the material of the insert on the variation of the equivalent elastic strain field}

For a comparative purpose, we chose another material from the semi-metallic matrix composite wafer, and keeping the same disc material and the same boundary conditions, the mechanical properties of which are given in the Table 4.

Figs. 8 and 9 show a comparison between the equivalent elastic deformations for the two pairs of materials (gray cast iron / composite with organic matrix, and gray cast iron / composite with semi metallic matrix) during braking and in function of time for the two types of disc which are respectively (ventilated grooved disc / pads, and ventilated pierced

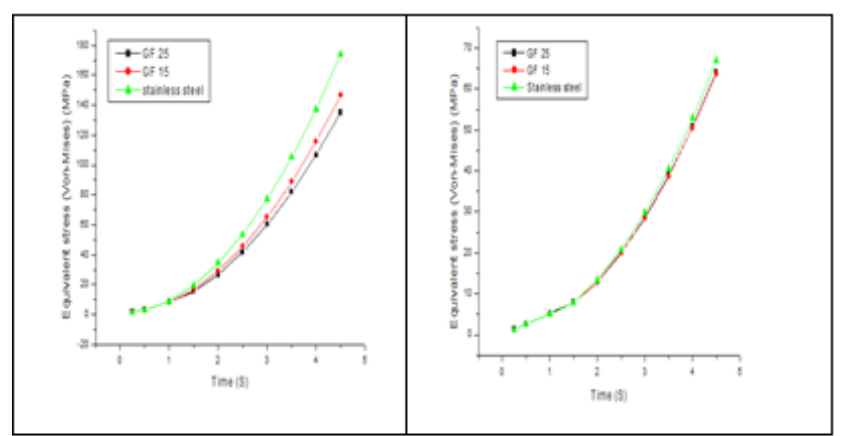

(a)

(b)

Fig. 7 The variation of the equivalent stress in the two couples under the influence of change of the material as a function of time; (a) Torque (ventilated grooved disc / pad); (b) The torque (ventilated drilled disc/pad)
Table 4 Mechanical properties of the materials composing the seals

\begin{tabular}{lcc}
\hline Mechanical properties & $\begin{array}{c}\text { Organic matrix } \\
\text { composite }\end{array}$ & $\begin{array}{c}\text { Semi-metallic } \\
\text { matrix composite }\end{array}$ \\
\hline Density $\left(\mathrm{kg} / \mathrm{m}^{3}\right)$ & 2500 & 6000 \\
Young's modulus $(\mathrm{Pa})$ & $3 \mathrm{E}+09$ & $5 \mathrm{E}+09$ \\
Compressibility modulus $(\mathrm{Pa})$ & $2 \mathrm{E}+09$ & $3.3333 \mathrm{E}+09$ \\
Shear modulus $(\mathrm{Pa})$ & $1.2 \mathrm{E}+09$ & $2 \mathrm{E}+09$ \\
\hline
\end{tabular}

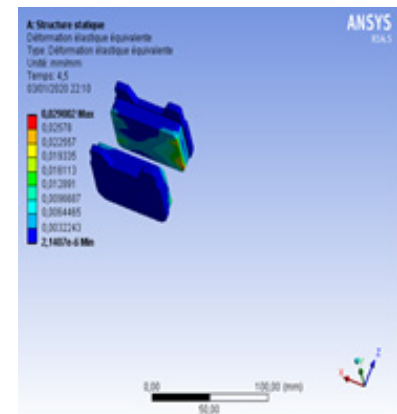

(a)

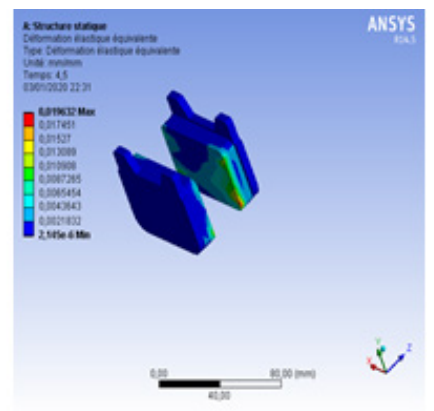

(b)

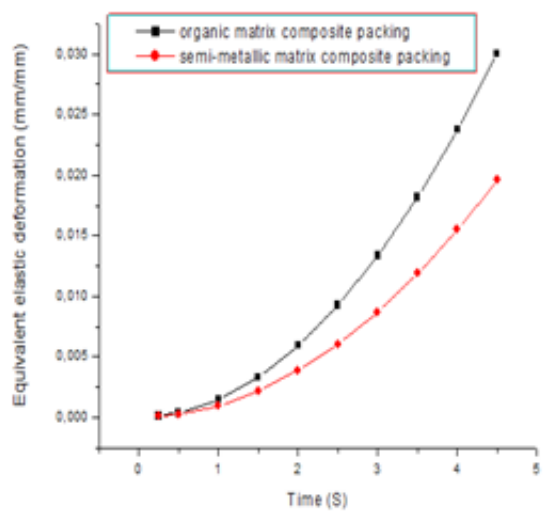

(c)

Fig. 8 Variation of the equivalent elastic deformation for the two couples (grooved disc in gray cast iron / composite with organic matrix, and gray cast iron / composite with semi-metallic matrix); (a) Torque (gray cast iron / organic matrix composite); (b) Torque (gray cast iron / semi-metallic matrix composite); (c) Variation of the equivalent elastic strain as a function of time

disc / pads). The equivalent elastic deformations propagate over all of the friction tracks of the linings with the larger values being located on the edges of the two plates.

The results obtained show that the deformations increase with time and greater for the contact of the couple (gray cast iron / composite with organic matrix) for the two types of grooved and drilled disc, while for the couple gray cast iron / composite with semi matrix -metallic, it is weaker. Composite wafers with a semi-metallic matrix are more resistant to temperature and wear than composite 


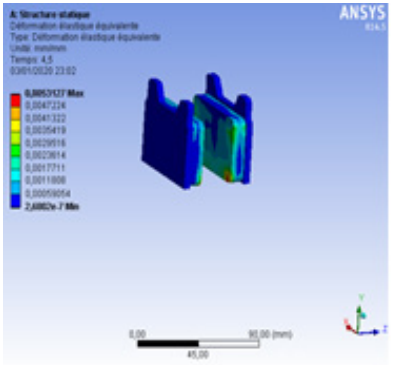

(a)

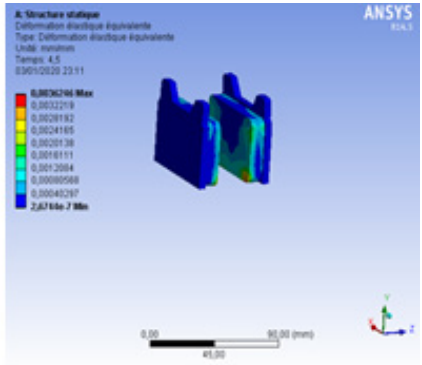

(b)

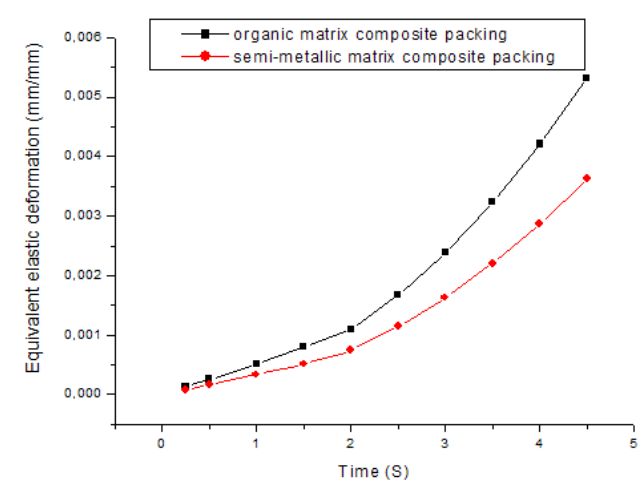

(c)

Fig. 9 Variation of the equivalent elastic deformation for the two couples (drilled disc in gray cast iron / composite with organic matrix, and gray cast iron / composite with semi-metallic matrix); (a) Torque (gray cast iron / organic matrix composite; (b) Torque (gray cast iron / semi-metallic matrix composite; (c) Variation of the equivalent elastic strain as a function of time

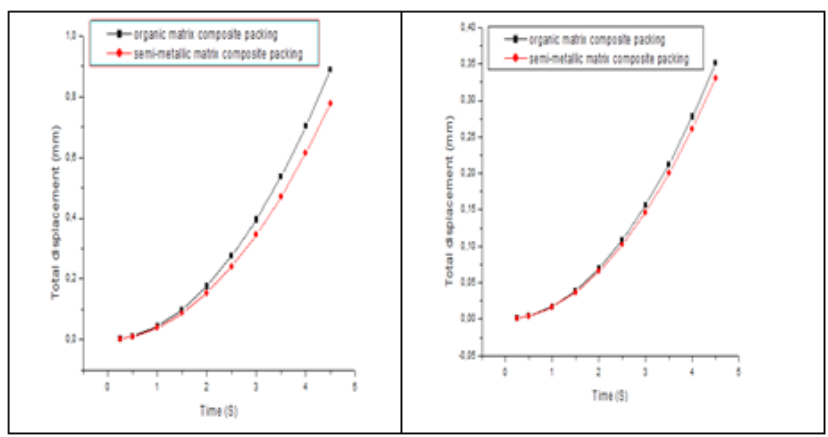

(a)

(b)

Fig. 10 Effect of changing pad material on displacement; (a) Torque (grooved disc in gray cast iron / organic matrix composite); (b) Torque

(drilled disc in gray cast iron / semi-metallic matrix composite)

wafers with an organic matrix, because of its properties which are resistant to high temperatures compared to organic, and that they have good mechanical properties. This type of brake pads is recommended for large displacements in city, road and sports use [11].

\subsubsection{Influence of change in the material of the insert} on the total displacement in the two torques

The curves of Fig. 10 present a comparison between the displacements of the two couples under the influence of the change of material of the linings. The results show that the field of total displacement in the couple (gray cast iron / composite with organic matrix) for the two types of discs become larger than in the pair (gray cast iron / composite with semi-metallic matrix), when the linings in semi-metallic materials are in contact with the disc which are more rigid under the effect of friction and the heat generated, than those of organic linings, this is explained by their higher physical and mechanical properties (Young's modulus, density, etc.) than that of organic linings. The behavior of the braking torque depends on the materials of the torque [12-14].

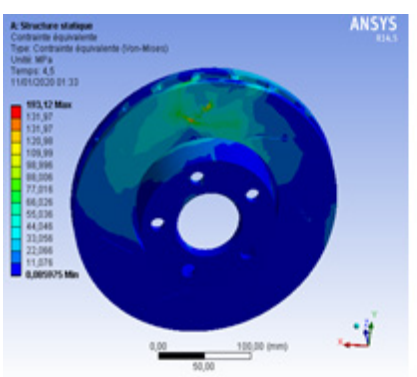

(a)

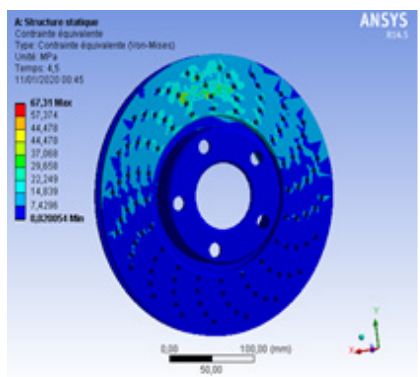

(c)

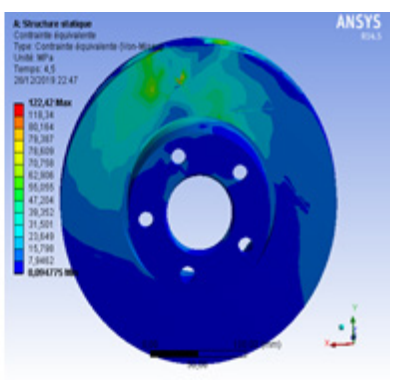

(b)

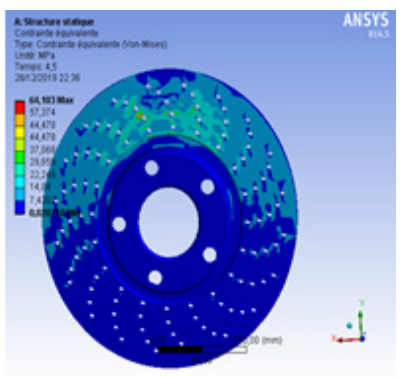

(d)
Fig. 11 Influence of a single piston and double piston caliper on the Von-Mises equivalent stress field; (a) Single piston caliper; (b) Double piston caliper; (c) Single piston caliper; (d) Double piston caliper

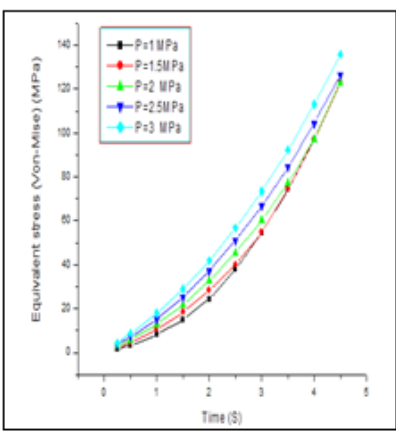

(a)

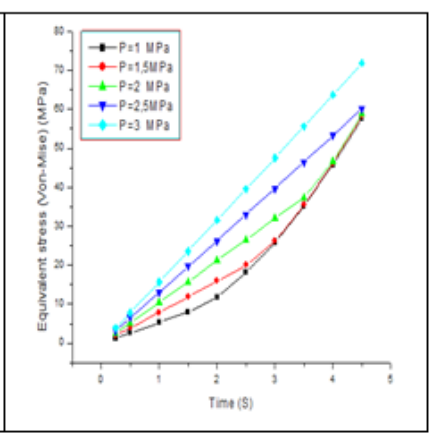

(b)
Fig. 12 Influence of the pressure on the field of the equivalent stress of Von-Mises; (a) Torque (grooved disc in gray cast iron / organic matrix composite); (b) Torque (drilled disc in gray cast iron / semi-metallic matrix composite) 


\subsection{Influence of the pressure on the equivalent stress field of Von-Mises}

For Figs. 11 and 12 it can be seen that the values of the equivalent stress increase during contact between the disc and the pads, and as a function of the braking time, when the pressure increases the shape of the curves is the same, there is not much difference between the five curves for the two couples, but the difference increases with time.

\subsection{Influence of a single piston and double piston caliper on the Von-Mises equivalent stress field}

In the braking system, the pads which come to press the disc and which generate friction during braking, the mechanical loading is represented by the pressure of a hydraulic piston applied to the pads.

If we compare the results of the equivalent stresses obtained for the two cases of a single piston and double piston caliper applied to the pads, maintaining the same boundary conditions, and the same choice of the material of the disc and the pads for the two couples.

In the case of a double piston caliper (pressure), the results of the stresses obtained previously show that the stress distribution propagates over the entire surface of the disc and at the level of the contact zone with values lower than those obtained in the case of the single-pressure caliper. The concentration of the stress in the contact zone propagates towards the bowl zone of the disc and towards the fins during braking. These constraints undergo severe damage (cracking of the fins, and fixing holes, which can cause a rupture of the bowl).

We conclude that a mechanical loading applied to double pressure pads produces a better distribution of the Von-Mises equivalent stress in the braking torque.

\section{Conclusion}

The simulation results obtained in dry sliding contact between a disc and a pad during braking as a function of

\section{References}

[1] Benramdane, M., Khadraoui, Y., Bibi Triki, N.. "Analysis of the contribution of thermal transfer from uniformly heated rotating discs (brake disc)", In: 21st International Conference "Mechanics -2016", Kaunas, Lithuania, 2016, pp. 17-32.

[2] Carneiro Esteves, A., Winocq, L., Berthaud, J.. "Disc brakes of trucks: a technical innovation for heavy vehicles", In: Total Vehicle Dynamics: Technical Papers: XXIV FISITA Congress, London, UK, 1992, pp. 165-174.

[3] Chrétien, G. "Matériaux composites à matrice organique" (Composite materials with organic matrix), $\mathrm{PhD}$ Thesis, National Institute of Applied Sciences of Lyon 1986. (in French) time were determined in terms of equivalent stresses of Von-Mises, and equivalent elastic deformation, and displacement. The comparison between the results of the two braking couples (grooved ventilated disc / pads, and pierced ventilated disc / pads) which are influenced by the parameters obtained previously shows that:

- The drilled disc resists better than the grooved disc, due to the perforations, which allow rapid cooling and guarantee better heat dissipation capacity compared to the grooved disc.

- Gray cast iron is the most commonly used in the automotive industry which has a high carbon content, ensures good thermal behavior and good mechanical resistance, deprives the breaking strength and the modulus of elasticity, low wear, can resist cracking better despite high temperature [5, 9].

- Composite wafers with semi-metallic matrix better withstand temperature and wear than composite wafers with organic matrix, because of its properties, which withstand high temperatures well compared to organic ones. They have good mechanical properties. This type of brake pads is recommended for large displacements in city, road and sports use [5].

- The field of the total displacement in the couple (gray cast iron / composite with organic matrix) for the two type of the disc becomes larger than in the couple (gray cast iron / composite with semi-metallic matrix).

- The Mises pressure positively influences the stress. The equivalent stress increases during contact between the disc and the pads when the pressure is increased.

Mechanical loading applied to double pressure pads produces a better distribution of the equivalent Von-Mises stresses in the braking torque.

[4] Djafri, M. "Numerical and experimental study of the tribological behavior of sliding contacts - Application to disc brakes", Doctoral dissertation, The Mohamed Boudiaf Oran University, 2014.

[5] Nguyen-Tajan, T. M. N. "Modélisation thermomécanique des disques de frein par une approche eulérienne" (Thermomechanical modeling of brake discs using a eulerian approach), PhD Thesis, École Polytechnique X, 2002. (in French)

[6] Baklouti, M. "Tribological analysis of the role of constituents in the performance of organic composite materials for brake linings", Doctoral dissertation, The Shax University, 2013. 
[7] McGeer, T. "Passive Dynamic Walking", The International Journal of Robotics Research, 9(2), pp. 62-82, 1990. https://doi.org/10.1177/027836499000900206

[8] McGeer, T. "Passive Dynamic Walking", The International Journal of Robotics Research, 9(2), pp. 62-82, 1990. https://doi.org/10.1177/027836499000900206

[9] Al-Kamaki, Y. S. S., Al-Mahaidi, R, Bennetts, I. "Experimental and numerical study of the behaviour of heat-damaged RC circular columns confined with CFRP fabric", Composite Structures, 133, pp. 679-690, 2015.

https://doi.org/10.1016/j.compstruct.2015.07.116

[10] Hedayatnasab, Z., Eslami-Farsani, R., Khalili, S. M. R., Soleimani, N. "Mechanical characterization of clay reinforced polypropylene nanocomposites at high temperature", Fibers and Polymers, 14(10), pp. 1650-1656, 2013.
[11] Abdoli, H., Saebnouri, E., Sadrnezhaad, S. K., Ghanbari, M., Shahrabi, T. "Processing and surface properties of Al-AlN composites produced from nanostructured milled powders", Journal of Alloys Compounds, 490(1-2), pp. 624-630, 2010. https://doi.org/10.1016/j.jallcom.2009.10.121

[12] Smagorinski, M. E., Tsantrizos, P. G., Grenier, S., Cavasin, A., Brzezinski, T., Kim, G. "The properties and microstructure of Al-based composites reinforced with ceramic particles", Materials Science and Engineering: A, 244(1), pp. 86-90, 1998 https://doi.org/10.1016/S0921-5093(97)00830-7

[13] Lee, S. Y. "Finite element dynamic stability analysis of laminated composite skew plates containing cutouts based on HSDT", Composites Science and Technology, 70(8), pp. 1249-1257, 2010. https://doi.org/10.1016/j.compscitech.2010.03.013

[14] Plagenhoef, S., Gayner Evans, F., Abdelnour, T. "Anatomical Data for Analyzing Human Motion", Research Quarterly for Exercise and Sport, 54(2), pp.169-178, 1983. https://doi.org/10.1080/02701367.1983.10605290 